\title{
Important Function of Development of Rural Female Human Resources for Promoting Modern Agricultural Development
}

\author{
Jingwen Luo \\ School of Management, China West Normal University, Nanchong, 637009, China
}

Keywords: Rural females; Human resources; Modern agriculture; Path

\begin{abstract}
As an important constituent part of human resources, female human resources are not only important object and carrier for the formation of human capital, but also undertaker of the responsibility for cultivating and recovering human resources. Therefore, China should take the development of female human resources as a major objective of national resource construction, especially rural female human resources of a larger proportion. This paper explains reasons for backward development of rural female human resources, analyzes their influence on modern social agriculture and puts forward corresponding development strategies for improving the influence of the development of rural female human resources on modern agricultural progress.
\end{abstract}

\section{Introduction}

Modern agricultural development and construction requires the effort and input of all people and peasants with cultural connotations and technical ability in the new era, including rural females. Since the foundation of New China, the development of rural female human resources in China is not ideal. Many rural females are still too traditional without advanced social consciousness and modern agricultural awareness. Therefore, they cannot be important forces of agricultural production. This seriously restrains the sustainable development of Chinese agriculture. Therefore, to promote Chinese modern agricultural development rapidly, rural female human resources must be developed and expanded as an important task so that they can keep pace with the era development and have the social consciousness of new rural females in the new era.

\section{Analysis on reasons for backward development of rural female human resources}

The development of Chinese rural female human resources is not very smooth due to the influence of traditional culture, awareness and cultural quality of females. It is no wonder that the development is backward.

\section{Gender division of labor and positioning under traditional male system}

Difference in social division of labor caused by gender difference is always a part that cannot be discarded in Chinese traditional concept, which results in unfair careers of males and females in public areas and great gap between their responsibilities. On the whole, Chinese traditional social development is at the cost of sacrificing females and results in the maximum reflection of male social value. Such social mechanism with male supremacy is traditional cognitive ideology for males and females in China. If females only play an auxiliary role in labor activity, the labor strength of females should not be higher than that of males. However, the result is really not so. In China, the housework time of rural females per capita is 4.23 hours, which is more than 2.82 hours of males. The mean value of housework undertaken by females is 5.38 , accounting for $66.63 \%$ of the total value. This indicates that Chinese rural females undertake excessive amount of labor while undertaking special human capital accumulation and development responsibility. However, in fact, this "men managing external affairs and women managing internal affairs" social structure in rural areas will not promote the comprehensive development of Chinese agricultural production and will marginalize interests of female groups. 


\section{Low educational status of rural females}

The main manifestation of marginalization of interests of rural female groups is low educational status. China is not a modernized country now. It is a power of illiterate population. Among about 98.32 million illiterate population, females account for over $70 \%$, most of whom are in rural areas. Currently, 60.77\% female children between 10 and 14 years old in rural areas are uneducated. This figure indicates that Chinese rural human resources cannot be fully development and shows the lack of cultural education caused by social and economic environment. Rural females cannot and are unable to participate in the development of human resources. Therefore, their disadvantage in education makes them lack the mastery of technology and culture. The positive influence of rural females on modern agricultural development is out of the question. The development status of rural female human resources produces some negative influence on Chinese modern agricultural development.

\section{Negative influence of development status of rural female human resources on modern agricultural development}

\section{Influence on the development of agricultural science and technology and technology promotion}

Currently, comprehensive scientific and technological modernization of agriculture has been realized in many regions in China, including the modernization of tools, agricultural cultivation management and operation and planting technology. However, as Chinese rural females show weaknesses in this aspect such as low cultural quality and inadaptation to new equipment and technologies, rural agricultural development with most females as the main force of production is hindered. That is, science and technology cannot be transformed into practical productivity. Therefore, it hinders the large-scale promotion of new technology and achievements of agricultural science and technology and influences the progress of rural agricultural modernization development.

\section{Influence on adjustment of rural agricultural industrial structure}

Chinese rural females are characterized by low cultural quality, technical skills and level of industrial structure involved and excessive extensive operation, illiteracies and surplus laborers. These features determine that Chinese rural females can only be engaged in some simple planting and cultivation work. Currently, rural agricultural industrial structure has changed greatly under the social development background that most rural males follow the general trend of urbanization and work in cities. If rural females cannot shoulder agricultural production or adapt to modernized agricultural production as soon as possible, urbanization which is a policy benefiting both the country and citizens might restrict rural agricultural economic development.

\section{Influence on intensive development of rural agriculture}

Chinese agriculture always advocates the transition from extensive agricultural growth to intensive development and adheres to the business pattern of appropriate scale. However, the current agricultural development pattern under family contracting responsibility system cannot achieve modern agricultural development. Therefore, China conducts optimal configuration of agricultural production and relevant operating elements by means of regional layout, socialized service and specialized production and then develops functions of the tertiary industry such as rural agricultural economic ecology and tourism, recreation and sightseeing. However, such commodity economic development trend obviously cannot answer the management and operation concept and awareness of Chinese rural females. Therefore, with respect to market operation concept, few Chinese rural females can manage the rural market effectively and control the production with agricultural economic management system. China cannot realize modernized management and operation in the development of rural female human resources and it is urgent to improve cultural and technical quality of rural females so as to develop a majority of labor forces flexibly and accelerate the development of modernized agriculture. 


\section{Practical significance of the development of rural female human resources for promoting modern agricultural development}

\section{Necessary requirement for improving rural physical productivity}

The winner of Nobel Prize in Economics and famous American economist Theodoor W Schurz thinks that human capital plays a decisive role in the development of social economy, especially rural agriculture because the ability and quality of people are often the key to wealth. Traditional females can break through the bottleneck of social concept and set up their own value and social status, which is the reason for the increase of agricultural capital over 5 times in America during the half century. Therefore, the improvement of rural females' ability and quality can directly influence the development of modern agriculture. In recent years, China has gone through great adjustment of rural agricultural industrial structure. With the constant advance of urbanization, a large batch of male labor forces has gone to urban areas gradually for establishing a business. Therefore, rural females have to undertake and dominate a large number of rural agricultural production tasks. According to statistics, the proportion of total output value of agricultural production dominated by rural females has increased from $34.2 \%$ to $61.3 \%$ from 2006 to 2014. The rise is the highest since the foundation of New China. A batch of female-dominated specialized households and peasant entrepreneurs has emerged successively in various rural regions. This means that Chinese rural females have gradually become the main force of agricultural production.

\section{Development of courtyard economy}

The National Bureau of Statistics in China conducted a general survey on incomes of domestic peasant households in 2014 and found that 1/3 incomes of peasant households came from courtyard economy. Courtyard economy refers to female economy in general sense. According to data presentation of the National Bureau of Statistics, the per capita net income of rural residents was 2930 Yuan in 2005 and the Engel' s Index of rural families was 46.7 at that time. However, China greatly adjusted rural female human resources, strengthened corresponding skills of rural female labor forces in terms of the degree of support, channels of increasing income and exploration of internal potentials of agriculture and stimulated the degree of participation of rural females in agricultural production through effective guidance, thus improving the service efficiency of rural female human resources in China and increasing the income of rural residents on the whole. The per capita net income of Chinese rural residents reached 4320 Yuan with great increase by 2010.

\section{People-oriented}

It is no doubt to develop rural female human resources under people-oriented principle in this society with importance attached to equal men' $s$ and women' $s$ rights. It not only mobilizes the initiative and creativity of rural females in developing agricultural production positively, but also solves the problem of increasing shortage of rural labor forces ultimately and actually realizes urban-rural equilibrium of talent development. After rural females have the opportunity to learn new technical knowledge which greatly influences and changes their ideology, they gradually establish self-awareness and autonomous right, define their value orientation and greatly change their behavioral norms. For example, in terms of the concept of child-bearing, majorities of rural females get rid of the traditional concept of child-bearing, i.e. the more sons, the more blessings, and tend to give a good birth and good care. In China, the people-oriented rural female development strategy is constantly developing in the direction of improving the degree of education of rural females and utilizing and developing rural female human resources reasonably. This is conducive to the improvement of cultural and technical level of rural female labor forces and non-agricultural transformation of surplus labor of rural females. It conforms to the halo effect in western economics theory, i.e. the investment into female human resources will result in progressive increase of incomes of human capital which will bring infinite benefits to the society and benefit not only females, but also families, society and all human beings. The impact and significance of this halo effect for human beings is beyond comparison and irreplaceable by males. 


\section{Corresponding countermeasures for developing Chinese rural female human resources}

Economists think that human is always a special capital and individuals with knowledge, skills and experience can produce considerable economic value and production efficiency for organizations. Chinese rural females hold a large proportion in total population. Therefore, it is required to develop and utilize this resource so as to promote the development of Chinese modernized agriculture.

\section{Correct social gender consciousness}

The limited development of Chinese modern agriculture is a social chain reaction of traditional concepts in ancient times to a great extent. It reduces the social status of females invisibly, makes labor division between genders and social learning have great differences and slows down the step of agricultural progress. Therefore, we should get rid of this antiquated idea, exploit potentials of rural female human resources to the greatest extent, exert their social role as social persons, re-organize diversified rural female images, make rural females not only a wife and mother, but also a positive participant and pusher of social process and agricultural development process as males, provide good social environment for rural females to overcome negative mind such as resign to fate, self-abasement, timidity, compliance, flinch and blocking, allow them to actually understand the society and themselves, free their mind and overcome traditional concepts and integrate into the modern society, and establish equal talent evaluation indicator system for rural females.

\section{Improve economic status}

To realize equal social status of females, it is necessary to make them go to the society and integrate into agricultural socialized service, exploit their potentials fully, give them more social responsibilities and train and promote the development of rural females. In agricultural practice and construction, it is required to be bold to use female scientific and technical personnel, establish new projects and standards for rural females, enrich their management awareness and free them from heavy high-intensity physical work. This not only can protect the physical and psychological health of rural females, but also is a good plan for developing and mobilizing rural female human resources.

\section{Enrich scientific and cultural quality of rural females}

According to statistics, if the measure of strengthening the education for rural female labor forces is implemented per year, the gross national product will increase by about $8 \%$. Therefore, it is required to mobilize the initiative of rural female labor forces through education. Besides measures for the acceleration of reform of educational system under implementation, it is necessary to establish good educational joint conference mode with standardizing system, provide more convenient learning opportunities for rural females and create equal educational conditions for men and women. More importantly, it is required to strengthen rural basic education, start from children and further popularize and strengthen nine-year compulsory education, reduce the existence of young female illiteracies in rural areas ultimately, eliminate the phenomenon of young people deprived of education; seek for multi-channel raising of educational fund while establishing diversified school-running mode for basic education, and promote the comprehensive quality of rural labor forces especially females by improving school-running conditions and the welfare standard of rural teachers. For adults, it is necessary to create various classes for learning of professional agricultural techniques and skills appropriate to rural female labor production, help them popularize agricultural knowledge and establish a comprehensive, systematic and targeted female adult educational structure system so as to enrich their labor production knowledge and further promote the progress of rural agricultural development.

\section{Conclusion}

China is the largest country of human resources in the world. If rural female human resources can be fully developed and mobilized, it will promote modern agricultural development greatly. The development of rural female human resources not only concerns the development of rural agriculture, but also concerns the overall quality and national quality of future rural populations in China. It is 
also an objective demand of the construction of new rural area and the development of new modernized agriculture.

\section{Acknowledgments}

This paper is a specialized project of research fund of young teachers in China West Normal University. Project name: Development of Human Resources in "Hollow Village" under the Vision of Urbanization. Project number: 13D026

\section{References}

[1] Huang Wen. Industrial Development and Development of Rural Female Human Resources Take Western Regions for Example. Shaanxi Journal of Agricultural Sciences, 2013,59(4):231-234.

[2] Huang Wen. Role of Development of Rural Female Human Resources in Modern Agriculture. China Science and Technology Forum, 2008(5):132-135.

[3] Ye Lingzhen. First Exploration on Development of Rural Female Human Resources and Construction of Socialist New Countryside . Fujian Normal University,2007.34-42. 